\title{
A NATURALIZAÇÃO DA DISCRIMINAÇÃO RACIAL EM PORTUGAL
}

\author{
ROVÊNIA AMORIM BORGES ${ }^{1}$
}

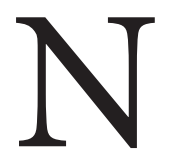

estes tempos atuais de migrações, movimentos de refugiados e discursos extremistas contra os fluxos humanos no sentido sul-norte, pergunta-se: Portugal pode ser considerado um exemplo de país tolerantepara com a pluralidadedas diferençashumanas ou, em contraste, éum exemplo de como se processa, historicamente, a naturalização da discriminação étnica e racial? Uma rápida leitura de notícias publicadas em 2019 é suficiente para perceber o quanto essa complexa questão obteve espaço nos mass media, suscitando reflexões trazidas por políticos, intelectuais e ativistas, sobretudo após a proposta de recolher, pela primeira vez em nível censitário, dados étnicoraciais da população portuguesa.

É no contexto desse atual e acalorado debate público que o livro Preto e branco: a naturalização da discriminação racial, de autoria de Rosa Cabecinhas, publicado em 2017 pelas Edições Húmus, merece ser resgatado como referência sobre o racismo em Portugal. Professora da Universidade do Minho, com linha investigativa centrada nas áreas da diversidade, comunicação intercultural e discriminação social, a autora contextualiza o conceito de raça no período pré e pós 25 de abril de 1974, por meio das teorias da psicologia social, para a compreensão dos processos psicossociais subjacentes à discriminação étnico-racial e à construção da identidade nacional.

A autora faz uma verificação empírica do conceito cognição social, que diz respeito à forma como diferentes integrantes de grupos sociais percebem os outros e a si mesmos, tendo em conta não só os estereótipos sociais, mas também os efeitos da categorização social da população portuguesa. No total, dois mil estudantes portugueses e angolanos do ensino superior em Portugal contribuíram para o encadeamento teórico-metodológico de seis estudos empíricos que possibilitaram perceber como o racismo se processa no senso comum.

O livro está dividido em seis capítulos, que totalizam 307 páginas, três dedicados à revisão teórica e apresentação de conceitos próprios da psicologia social e os demais à discussão dos estudos empíricos. Resultado da tese de doutorado da autora, o trabalho investigativo foi premiado em 2004 pelo Alto Comissariado para a Imigração e as Minorias Étnicas por evidenciar a existência de um racismo naturalizado em Portugal e oferecer um prisma de análise das desigualdades sociais para além das condições de classe, sem ignorar a perspectiva dos grupos discriminados.

A investigação foi iniciada há duas décadas, mais exatamente em 1997, Ano Europeu contra o Racismo e as subsequentes campanhas realizadas nos meios de comunicação social, escolas e associações de jovens com o objetivo de despertar a consciência sobre o racismo. Nessa época, Portugal, um país ainda muito marcado pela emigração, começava a tornar-se um destino para 
imigrantes, provenientes tanto de países europeus quanto das ex-colônias portuguesas. Foi nesse contexto de efervescência discursiva que Rosa Cabecinhas se debruçou para desvelar o racismo como um fenômeno social fortemente enraizado em muitos setores da sociedade portuguesa.

Duas décadas depois, o tema voltou a ter centralidade. No debate público que se trava atualmente, há aqueles que se posicionam contra a recolha de dados étnico-raciais sob o argumento central de que reunir informações por categorias identitárias contribuiria para segregar o povo português. No entanto outras vozes sustentam que a invisibilidade das identidades sedimenta percursos históricos e ideologias hegemônicas que contribuem para a perpetuação das desigualdades sociais e raciais. O livro Preto $e$ Branco ajuda-nos a perceber raça como um conceito revigorado e alargado enquanto construto social, histórico e político para explicar os racismos latentes e negados no Portugal do século XXI.

Ao emoldurar a sua investigação por um olhar eurocêntrico, a autora acaba por privilegiar a "perspectiva ocidental, não só na revisão da literatura como na recolha dos dados" (CABECINHAS, 2017, p. 281). Dessa forma, fica em evidência uma lacuna na revisão da literatura. São desconsideradas a gênese do termo raça no colonialismo da América Ibérica e a contribuição histórica de Portugal para a expansão das hierarquias raciais a partir do século XVI, tendo em vista o sistema-mundo "imperialista/ ocidentalcêntrico/cristãocêntrico/capitalista/patriarcal/moderno/colonial” (GROSFOGUEL, 2012, p. 93).

O laboratório colonial português inaugurado no Brasil, e que está na origem da construção social que legitima a hierarquia racial dos portugueses sobre os indígenas e africanos escravizados, não foi, assim, problematizado. A autora prioriza as teorias do racismo científico em voga na Europa do século XIX e, em menos linhas, o lusotropicalismo de Gilberto Freyre, adotado como doutrina oficial pelo Estado Novo português no período pós-Segunda Guerra Mundial. Por conseguinte, de forma que me parece equivocada, a autora situa a genealogia do racismo na Europa do fim do século XVIII.

Ao desconsiderar as raízes da discriminação racial no Brasil colônia, ela escamoteia um racismo que alguns intelectuais e políticos portugueses, desde o regime salazarista, têm se esforçado por desvincular da epopeia dos chamados descobrimentos, renegando, conforme nos lembra a socióloga Cristina Roldão, o papel central que Portugal teve na "produção do racismo e na construção de uma diáspora subalternizada dos negros no mundo" (HENRIQUES, 2019, p. 20). Para os teóricos descoloniais, a chegada do europeu à América marcou o surgimento de "identidades históricas e geoculturais" (o índio, o negro, o branco e o mestiço) originárias do novo padrão de poder do "mundo colonial capitalista” e "impostas depois como categorias básicas das relações de dominação e como fundamento de uma cultura de racismo e etnicismo" (QUIJANO, 2014, p. 757).

Por outro lado, para a autora, o fim do racismo científico não significou o fim do racismo, mas o início da sua transformação e diversificação, resultando numa "multiplicidade" de manifestações (CABECINHAS, 2017, p. 28). Neste aspecto, ela apresenta uma linha de pensamento que encontra paralelo às críticas descoloniais, a exemplo do sociólogo Boaventura de Sousa Santos (2019, p. 7), para quem o racismo é uma das maneiras pelas quais o colonialismo se perpetua até os nossos dias.

Convém salientar que a autora traz um importante contributo para o debate sobre o racismo em Portugal: o deslocamento do conceito da raça em conformidade com as características fenotípicas elencadas pelas teorias do racismo científico para o de grupos étnicos, quando então a classificação das pessoas passa a ser feita em função da diferenciação cultural. Para o senso comum, o significado do conceito cultura é percebido de modo análogo ao de raça. Ou seja, "a um processo de racialização seguiu-se um processo de etnização" (CABECINHAS, 2017, p. 35), em que as diferenças culturais passaram a ser o distintivo de superioridade ou de inferioridade dos povos. 
É com base, portanto, na premissa de um racismo naturalizado, atualizado e incrustado na sociedade portuguesa que a investigadora buscou perceber como estudantes portugueses e angolanos interiorizam preconceitos e comportamentos discriminatórios provenientes do racismo. Esta investigação demonstrou que, muito embora as premissas do racismo científico tenham sido abolidas há décadas em Portugal e na Europa e as campanhas de sensibilização da opinião pública tenham sido intensificadas a partir de 1997, as tipologias raciais "continuam a estruturar o pensamento do senso comum" (CABECINHAS, 2017, p. 270) e a compor hierarquias sociais, agora baseadas na nacionalidade e na cor da pele.

Nessa dupla e conjugada classificação social, ainda que política, administrativamente rejeitada e não institucionalizada pelo governo português, os portugueses estão no topo do estatuto social, enquanto os asiáticos ocupam o nível intermédio e os africanos, provenientes dos antigos territórios coloniais, as posições mais inferiorizadas, à frente apenas dos ciganos. Em relação à hierarquização em função da cor da pele, aos brancos foi atribuída uma posição social superior à dos negros se comparado os dois sistemas de classificação (por origem nacional e por cor da pele): "O estatuto social atribuído aos brancos foi semelhante ao atribuído aos portugueses" (CABECINHAS, 2017, p. 271, grifos do original).

Por fim, acresce a autora, o racismo em Portugal manifesta-se por negar o reconhecimento da singularidade do outro:

Na prática, isto significa que os membros das minorias não são tratados como "indivíduos", mas simplesmente como "representantes" de uma categoria homogénea [...]. Assim, os membros das minorias tornam-se "invisíveis" enquanto pessoas, mas extremamente "visíveis" enquanto grupo (CABECINHAS, 2017, p. 280-281).

Por este ângulo, o racismo em Portugal abarca formas de discriminação racial e étnica e deve ser analisado tendo em consideração as relações históricas de poder entre os grupos, o contexto cultural e as ideologias dominantes.

\section{Referências}

CABECINHAS, R. Preto e branco: a naturalização da discriminação racial. 2. ed. Famalicão: Húmus, 2017.

GROSFOGUEL, R. El concepto de "racismo" em Michel Foucault y Frantz Fanon: ¿teorizar desde la zona del ser o desde la zona del no-ser? Tabula Rasa, Bogotá, n. 16, p. 79-102, jan./jun. 2012. https:// doi.org/10.25058/20112742.112

HENRIQUES, J. G. Centenas debatem o que é ser negro na Europa “nos seus próprios termos”. Público, Lisboa, p. 20, 4 jul. 2019.

QUIJANO, A. "Raza”, “etnia” y “nación” en Mariátegui: cuestiones abiertas. In: QUIJANO, A. Cuestiones y horizontes: de la dependencia histórico-estructural a la colonialidad/descolonialid del poder. Buenos Aires: Clacso, 2014. p. 757-775.

SANTOS, B. S. Descolonizar o saber e o poder. Público, Lisboa, p. 7, 18 jul. 2019. 


\section{Sobre a Autora}

Rovênia Amorim Borges é jornalista e doutoranda em Ciências da Educação, na especialidade de Sociologia da Educação e Política Educativa, na Universidade do Minho, Portugal, e investigadora do Centro de Investigação em Educação do Instituto de Educação (Cied). É mestre em Educação pela Universidade de Brasília, Brasil, com linha de pesquisa sobre a interseccionalidade de gênero, raça e classe na mobilidade internacional de estudantes brasileiros, numa perspectiva da descolonialidade de poder.

Recebido: 12 Ago 2019. Aceito:18 Nov 2019. 